\title{
Os condomínios agrícolas de armazéns em Palotina - PR ${ }^{1}$
}

\section{Agricultural storage condominiums in Palotina - PR}

\author{
Helton Jaques Albiero* \\ Diane Belusso*
}

\begin{abstract}
Resumo: Este artigo objetiva apresentar os condomínios agrícolas de armazéns como uma estratégia recente para a manutenção de produtores de soja e milho no município de Palotina, localizado na Mesorregião Oeste do Paraná. Por meio de pesquisa documental e bibliográfica, foi contextualizada a organização social dos agricultores e, por meio de pesquisa de campo, foi caracterizada a estrutura de funcionamento de um condomínio de armazenagem. Verificouse que o cooperativismo empresarial é uma prática tradicional em Palotina, pois contribuiu para o processo de modernização da agricultura e, atualmente, impulsiona o agronegócio.
\end{abstract}

Palavras-chave: Organização Social. Cooperativismo Agrícola. Armazenagem de grãos.

\begin{abstract}
This article aims at presenting the agricultural storage condominiums as a recent strategy for the maintenance of soybean and corn producers in the city of Palotina, located in the Western mesoregion of Paraná state, Brazil. Through documental and bibliographical research, the social organization of farmers was put in context, and through field research, the operating structure of a storage condominium was characterized. It was found that business cooperativism is a traditional practice in Palotina as it
\end{abstract}

\footnotetext{
${ }^{1}$ Uma versão preliminar deste texto foi apresentada no "II SEMINÁRIO INTERNACIONAL DE PÓS-GRADUAÇÃO EM DESENVOLVIMENTO RURAL SUSTENTÁVEL” em Foz do Iguaçu, entre 07 a 09 de agosto de 2019, sendo indicado pelo evento para compor este volume especial.

* Mestrando do Programa de Pós-Graduação em Sustentabilidade (PSU), associado entre a Universidade Estadual de Maringá (UEM) e o Instituto Federal do Paraná (IFPR) - Campus Umuarama; Especialista em Gestão Pública com Ênfase em Políticas Públicas pelo Instituto Federal do Paraná (IFPR); Graduado em Ciências Econômicas pela Universidade Estadual do Oeste do Paraná (UNIOESTE); Diretor de Planejamento e Administração do IFPR - Campus Assis Chateaubriand. E-mail: helton. albiero@ifpr.edu.br.

** Doutora em Geografia pela Universidade Estadual Paulista Júlio de Mesquita Filho, FCT/Unesp/Presidente Prudente (UNESP); Mestre em Geografia pela Universidade Estadual de Maringá (UEM); Graduada em Geografia pela Universidade Estadual do Oeste do Paraná (UNIOESTE); Professora do Instituto Federal do Paraná (IFPR), campus Umuarama. E-mail: diane.belusso@ifpr.edu.br.
} 
has contributed to the process of modernization of agriculture and currently boosts agribusiness.

Keywords: Social Organization. Agricultural Cooperativism. Storage of grains.

Recebido em 11/11/2019. Aceito em 10/03/2020.

\section{Introdução}

A importância da organização social, ao longo do tempo, é fonte de estudos em todas as áreas do conhecimento, com o objetivo de encontrar novos rumos que conduzam ao crescimento e desenvolvimento coletivo dos sujeitos e dos ambientes onde estão inseridos.

Em relação às cadeias produtivas, a força das organizações sociais assume uma dinâmica transformadora: culturalmente, a ampliação de conhecimentos por meio do convívio social; economicamente, por oportunizar aos associados possibilidades de maior geração de renda; ambientalmente, por fomentar a conscientização e a responsabilidade da utilização adequada dos recursos naturais (OLIVO, 2000).

De modo a introduzir a temática do presente artigo, é importante diferenciar os tipos mais comuns de organizações sociais agrícolas que coexistem no arranjo produtivo do município de Palotina, sendo estas: associação, cooperativa e condomínio.

Dentre essas instituições organizacionais agrícolas, a associação, se caracteriza basicamente pela união de duas ou mais pessoas, com objetivos comuns, que por intermédio desta união se fortalecem, criando possibilidades de obtenção de melhores condições e benefícios da comunidade constituída. Não há capital social envolvido, ou seja, os associados não são proprietários da associação (CARDOSO; NOGUEIRA; RODRIGUES, 2014).

Por sua vez, a organização cooperativa se caracteriza pela união livre e formal entre, no mínimo, vinte associados que, de modo coletivo e por meio de uma gestão democrática e participativa, procuram comercializar as suas produções e adquirir insumos variados. Por meio desta relação de compra e venda, conseguem gerar renda aos cooperados. Esta renda, após aprovação em assembleia geral, terá sua destinação definida de modo a atingir objetivos econômicos e sociais, com a finalidade de garantir o bem comum dos envolvidos. Existe a formação de capital social, e a constituição da pessoa jurídica com deveres e obrigações comuns aos cooperados (CARDOSO; NOGUEIRA; RODRIGUES, 2014).

Já a organização denominada condomínio, objeto principal deste estudo, trata-se de uma organização associativa pela qual seus participantes, pessoas físicas e geralmente avizinhados, se unem para, em conjunto, constituir legalmente uma sociedade por cotas, com o objetivo principal de obter melhores e maiores resultados para a sua produção. Este objetivo está relacionado também ao compartilhamento de toda a infraestrutura física e demais benefícios que são proporcionalmente divididos entre os participantes do condomínio. A constituição do capital social é dividida em cotas, onde cada condômino responde proporcionalmente ao seu percentual participativo da sociedade (OLIVO, 2000). 
O Serviço Nacional de Aprendizagem Rural (SENAR, 2011) define o condomínio agrícola como um modelo associativo pelo qual seus associados se unem legalmente para enfrentar os desafios de um mercado cada vez mais competitivo e globalizado, possibilitando maior rentabilidade econômica.

Para Olivo (2000), os condomínios se caracterizam como sociedades formadas por produtores rurais vizinhos, criados com a finalidade de oferecer condições de superação de adversidades econômicas e sociais de modo a possibilitar melhores condições para competir no mercado.

Em relação à produção de grãos e considerando a relevância das culturas temporárias de milho e soja no cenário das exportações brasileiras, todas estas organizações sociais relacionadas ao associativismo assumem importância fundamental para o arranjo produtivo das regiões onde estão inseridas, e neste caso em análise, do município de Palotina.

Este artigo, portanto, ao trazer o tema dos condomínios agrícolas de armazéns, demonstra como a organização social vem se reinventando no meio agrícola palotinense. Os agricultores de Palotina vinculados a uma grande cooperativa fundada na década de 1960, recentemente se vincularam aos condomínios de armazéns. São tradicionais produtores agrícolas que estão se mantendo viáveis mesmo diante da competitividade dos mercados agrícolas. Neste caso, objetivamos explicar como se deu a implantação e o funcionamento dos condomínios de armazéns no município de Palotina.

No ano de 2006, um grupo de 13 agricultores, vizinhos de terras entre si, se reuniu e após planejamento e estudo decidiram construir o primeiro condomínio de armazéns em Palotina. Como possibilidade de otimização do sistema produtivo de suas áreas agrícolas, o condomínio garantiria maior lucratividade, autonomia, liberdade comercial e ainda, de maneira isonômica, assistência técnica e divisão dos lucros, benefícios e responsabilidades proporcionalmente à participação de cada membro neste novo modelo de associativismo (FAEP, 2014).

Em 2019, estavam em atividade quatro condomínios agrícolas e, juntos, atendiam diretamente a 55 produtores de soja e milho, com diferentes capacidades produtivas entre si e que por meio desta nova forma de associativismo buscam maior autonomia comercial e por consequência maior valorização agregada ao seu produto.

O surgimento de um novo modelo de associativismo vem ganhando espaço no meio rural do município de Palotina. A organização de condomínios de armazéns desperta a curiosidade científica e, principalmente, a necessidade de estudos e pesquisas que possibilitem verificar os seus efeitos para a manutenção e sustentabilidade dos empreendimentos agrícolas.

Trata-se de uma pesquisa qualitativa, pois o interesse está no aprofundamento da compreensão do surgimento dos condomínios agrícolas como um novo modelo de organização social formada por agricultores no município de Palotina. A pesquisa qualitativa se preocupa com aspectos da realidade que não podem ser quantificados, centrando-se na compreensão e explicação da dinâmica das relações sociais (SILVEIRA; CóRDOVA, 2009, p. 32).

Quanto à amostra, Silveira e Córdova (2009, p. 32) ensinam que a pesquisa qualitativa tem o "objetivo principal de produzir informações aprofundadas e ilustrativas, sem se preocupar com o tamanho destas, pois a importância do estudo está na capacidade de que este conhecimento seja capaz de produzir novas informações". Neste caso, foram coletadas informações in loco, nos quatro condomínios instalados em Palotina, por meio de entrevistas semiestruturadas, com os gerentes dos condomínios, para obtenção de informações gerais. Especificamente, a todos os condôminos foi distribuído um questionário, que foi respondido apenas por aqueles que decidiram contribuir com a pesquisa por livre vontade. 
O texto foi organizado em três seções, além desta introdução e das considerações finais. A primeira é referente à caracterização do objeto de estudo, dados sobre o perfil agrícola do município de Palotina e dos condomínios de armazéns. Em seguida, é apresentado o contexto brasileiro do surgimento do sistema de condomínios agrícolas. A terceira seção apresenta a estrutura de funcionamento dos condomínios pesquisados in loco.

\section{Caracterização do objeto de estudo}

O município de Palotina, desde o início de sua colonização, em 1953, estabeleceu nas atividades agropecuárias o pilar para o seu crescimento e desenvolvimento econômico (TOMAZELLA, 2010).

Segundo a base de dados históricos do IPARDES (2019), o município de Palotina apresentava, em 2017, o total de 1.253 estabelecimentos agropecuários, distribuídos em uma área de 64.436 ha, o que representa aproximadamente $98,94 \%$ de toda a área do município.

O meio rural de Palotina é predominantemente agrícola e está centralizado no cultivo de soja e milho que representam a base da economia do município, em conjunto com os resultados da agroindústria local, somou, em 2016, o valor de $\mathrm{R} \$ 711.736 .574,00$, aproximadamente $45 \%$ do valor adicionado fiscal produzido no município (IPARDES, 2017).

De acordo com os dados coletados, referentes à produção de soja de 2017, o município de Palotina, com rendimento médio de $4.100 \mathrm{Kg} / \mathrm{ha}$, aparece entre os 74 municípios com as melhores médias produzidas no Brasil e o $15^{\circ}$ melhor no Estado, sendo ainda a $32^{\mathrm{a}}$ melhor média colhida deste grão na região Sul do Brasil composta por 1.191 municípios (IBGE, 2019).

Com o total de 183.680 toneladas, o município é o $134^{\circ}$ maior produtor nacional do grão, sendo o $13^{\circ}$ maior produtor paranaense e o $5^{\circ}$ maior produtor do Oeste do Estado (IBGE, 2019).

Uma condição histórica que contribuiu para a organização coletiva dos agricultores foi o fato de que a maioria dos pioneiros que adquiriram terras no Oeste Paranaense eram vizinhos ou possuíam algum grau de parentesco em suas regiões de origem - Rio Grande do Sul e Santa Catarina (REGINATO, 1979, p. 38).

Saquet e Sposito (2008, p. 17), se referem à territorialidade como uma "estratégia que permite influenciar ou controlar os recursos, fenômenos, relações e pessoas, e está intimamente ligada ao modo como as pessoas usam a terra, organizam o espaço e dão significado ao lugar [...]", entendimento que pode ser correlacionado ao movimento migratório que deu origem ao município de Palotina.

Para Hespanhol (2007, p. 271), “a maior parte dos pequenos municípios do interior do país é essencialmente rural e a dinâmica de funcionamento das respectivas cidades-sede é estabelecida a partir dos espaços rurais que a circunda".

Segundo o SENAR (2011), o processo associativo entre produtores possibilita um aprendizado contínuo de convivência e relacionamento, por intermédio da ajuda mútua e da cooperação. Macedo, Souza e Amodeo (2014) comentam que as cooperativas são organizações tradicionais no espaço rural e possuem a capacidade de intervir na realidade social do meio onde atuam tendo que dar respostas econômicas em um cenário competitivo.

De acordo com Hümmelgen (2016), o cooperativismo surge como uma doutrina, cuja finalidade é nortear uma associação de pessoas com interesses semelhantes, a fim de cooperarem e atingirem objetivos semelhantes. 
Para Nantes e Scarpelli (2012) é somente por meio da organização dos produtores e de ações coletivas, de forma coordenada, que eles poderão atingir de modo comum a todos seus membros. Quanto às estratégias para empreendimentos rurais, comentam:

As estratégias que determinam o sucesso dos empreendimentos rurais estão estreitamente vinculadas ao porte do produtor, pois, uma das razões fundamentais para a inserção em uma cadeia produtiva é a escala de produção. Essa escala é um dos fatores determinantes para o escoamento da produção, já que a comercialização dos produtos é função do volume de produção disponível (NANTES; SCARPELLI, 2012, p. 645).

A integração das ações, implementadas pelos diferentes órgãos públicos, cooperativas, sindicatos, associações de produtores, organizações não governamentais são de crucial importância para a dinamização econômica do campo e para a consequente melhoria da qualidade de vida de seus habitantes (HESPANHOL, 2007).

A origem de diferentes formas de cooperação está relacionada com o próprio processo de desenvolvimento da agricultura. Muitas são criadas espontaneamente pelos próprios agricultores, outras surgem mediante a intervenção de agentes externos como instituições governamentais, não-governamentais e agências internacionais de desenvolvimento (OLIVO, 2000, p. 43).

Filippi (2017), com base em estudos já realizados sobre a armazenagem no Brasil, analisou as características, perspectivas e viabilidade da estruturação de condomínios de armazéns de grãos. Conforme a autora: "Ressalta-se que neste caso, outras formas de associação não atendiam da maneira como o agricultor gostaria e necessitava" (FILIPPI, 2017, p. 47), por isso se organizaram em condomínio.

A importância da pesquisa científica sobre os condomínios e a escassez de literatura sobre o tema também foi evidenciada no estudo da autora, que relatou: "A maior parte do material sobre esse tema foi encontrada em notícias, relatórios técnicos, reportagens televisivas e revistas" (FILIPPI, 2017, p. 23).

A definição jurídica de condomínio encontra-se no Decreto $n^{\circ} 3.993$, de 30 de outubro de 2001, que regulamenta o art. 95-A da Lei no 4.504, de 30 de novembro de 1964, chamada de Estatuto da Terra. De acordo com o art. $2^{\circ}$ do referido Decreto, que institui o Programa de Arrendamento Rural para a Agricultura Familiar, condomínio é definido como sendo: um agrupamento de pessoas físicas ou jurídicas, constituído em sociedade por cotas, mediante fundo patrimonial pré-existente, com o objetivo de produzir bens, comprar e vender, prestar serviços, que envolvam atividades agropecuárias, extrativistas vegetal, silviculturais, artesanais, pesqueiras e agroindustriais, cuja duração é por tempo indeterminado (BRASIL, 2001).

\section{O surgimento do sistema de condomínio rural}

Historicamente, de acordo com Zamberlam (1993, apud OLIVO, 2000), os condomínios rurais foram adotados no Brasil a partir de 1974, em atividades relacionadas à suinocultura no estado de Santa Catarina, tendo como base os conhecimentos gerados a partir de seu uso junto a pequenos agricultores franceses.

Anjos, Estrada e Caldas (2011), identificaram o surgimento e propagação dos condomínios rurais, como modelo de associativismo no campo, a partir da década de 1980, especificamente na 
região Oeste do estado de Santa Catarina, que possuía por tradição e base econômico-financeira a suinocultura, que naquele momento atravessavam um momento de dificuldades estruturais e financeiras com o desenvolvimento da atividade.

Para Anjos, Estrada e Caldas (2011), a organização coletiva dos pequenos produtores locais em torno do sistema de condomínio, naquela época, foi significativa para a manutenção e expansão da suinocultura, possibilitando a viabilidade econômica do arranjo produtivo local.

Segundo dados de uma entrevista com um funcionário do governo, responsável pelo departamento das estatísticas agrícolas em Santa Catarina, havia 119 condomínios registrados no setor suinícola da região no final da década de 1980. Esses condomínios eram compostos por 1.369 produtores de suínos, empregando aproximadamente 5.500 pessoas (ANJOS; ESTRADA; CALDAS, 2011, p. 43-44).

Já no estado do Rio Grande do Sul, os condomínios rurais foram introduzidos em meados de 1988, a partir de modelos de Santa Catarina. Olivo (2000) analisou os modelos de condomínios rurais na bovinocultura leiteira do Rio Grande do Sul e destacou sua importância no fomento à produção leiteira das unidades de produção familiares, em pequenas propriedades, que no início da década de 1990 passavam por dificuldades.

Anjos, Estrada e Caldas (2011) identificaram o avanço do modelo associativo condominial para a agricultura, contudo, os autores indicam uma diferença fundamental na etapa cooperativa entre os setores, pois, contrariamente aos setores leiteiros e de suínos, onde a cooperação ocorre prioritariamente na fase inicial de produção com o acompanhamento técnico profissional, no setor agrícola, os resultados são obtidos com o armazenamento da produção no próprio condomínio, ou seja, o resultado da cooperação ocorre à jusante, no período pós-colheita.

Para Gullo (1997, p. 42) o condomínio rural foi concebido especialmente como uma forma associativa para agregar esforços coletivos que possibilitem efetivos resultados econômicos e sociais, viabilizando o trabalho dos pequenos produtores.

Verificou-se, contudo, que os condomínios rurais chegaram ao Brasil, na década de 1970, baseados em um modelo associativo francês. No Estado de Santa Catarina, surgiu como alternativa de inovação para alavancar a suinocultura das pequenas propriedades rurais. Posteriormente, na década de 1980, foi testado com êxito no setor de laticínio e bovinocultura no Rio Grande do Sul, onde avançou ainda para o setor agrícola em meados da década de 1990. Sempre direcionado ao pequeno produtor ou à pequena propriedade rural, com o objetivo fundamental de desenvolver determinadas atividades que até então haviam sido pouco desenvolvidas com a cooperação agrícola existente.

No caso de Palotina, a união entre os agricultores em torno de solucionar problemas recorrentes de armazenagem, logística de escoamento da produção, precificação do produto em períodos de entressafra e taxas de desconto no momento da entrega, os remeteu a experiências já vivenciadas por seus antepassados, os colonos pioneiros, que em meados dos anos 1960 enfrentaram obstáculos similares relacionados à armazenagem e comercialização.

Conforme se verificou, no município de Palotina/PR, mesmo anteriormente ao estabelecimento dos condomínios rurais, já existia uma tradição em relação à organização coletiva dos agricultores, exemplo disso foi a fundação de uma cooperativa agrícola em 1963, que ao longo de décadas foi consolidada e reconhecida pela atividade agroindustrial.

No município de Palotina, os condomínios de armazéns surgiram com o propósito de proporcionar ao produtor maior liberdade e autonomia na administração dos estoques físicos 
de sua produção, permitindo sua comercialização no momento mais propício, geralmente nas entressafras, visando maior rentabilidade financeira e a superação de alguns gargalos existentes à jusante da produção agrícola.

De acordo com a Federação da Agricultura do Estado do Paraná (FAEP, 2014) e confirmado no trabalho de campo, o modelo de condomínios para armazenagem compartilhada da produção agrícola foi inspirado em um condomínio localizado no município de Janiópolis/PR e adequado à necessidade inicial de 13 produtores de Palotina interessados em organizar e introduzir o modelo condominial na territorialidade do município, a partir do sonho comum de possuírem sua própria estrutura de armazenagem.

Destaca-se que a ausência de um planejamento estratégico nos moldes técnicos e conceituais, não foi empecilho para a sequência do projeto. Mesmo desconhecendo a ferramenta administrativa, estes agricultores se reuniram para compartilhar suas experiências, discutir ideias, analisar hipóteses e sugestões. Nestas discussões as estratégias eram abordadas em uma linguagem simplificada de modo a garantir a ampla participação dos envolvidos e seus familiares, além de buscarem informações junto a pessoas do município que possuíam alguma experiência com o armazenamento de grãos.

Ainda, de acordo com a pesquisa, foram necessários dois anos de planejamento e estudo para o processo se materializar no papel. A organização destes produtores somente foi possível graças ao comprometimento em comum de todos os interessados. Percebeu-se que os laços de parentesco, de amizades e de confiança se interpenetraram, sendo determinantes para o sucesso do empreendimento.

O primeiro condomínio agrícola de armazéns do município de Palotina, possui 14 condôminos e já passou por duas ampliações em sua capacidade de armazenamento, desde o início de seu funcionamento em 2006.

Motivados pelo êxito do primeiro condomínio instalado no município, outros três condomínios foram inaugurados e pertencem a outros 41 produtores agrícolas distintos. Em conjunto, estes 55 produtores do município de Palotina, cultivam aproximadamente 21.350 ha. Este montante, na maioria dos casos, se refere a várias pequenas e médias parcelas de área, localizadas na área rural do município de Palotina e de municípios vizinhos.

Neste processo histórico, foram identificados marcos importantes relacionados ao desenvolvimento do agronegócio no município de Palotina, do processo de colonização até o surgimento dos condomínios:

$\Rightarrow 1950$ - Início do processo migratório regional, voltado para a abertura de uma nova fronteira agrícola na região Oeste paranaense, visando o fortalecimento da economia nacional tendo como base a produtividade agropecuária. Ressalva-se que o município de Palotina foi fundado em 1953.

$\Rightarrow 1963$ - A introdução do cooperativismo, no início da década de 1960, representou uma nova etapa do agronegócio no município. O cooperativismo surge como estratégia no enfrentamento das dificuldades de armazenamento da produção, aquisição de insumos e equipamentos agrícolas, que proporcionaram o apoio necessário para a elevação da produtividade e a tecnificação da produção agrícola.

$\Rightarrow 1980$ - Os expressivos resultados alcançados com a cultura da soja, plenamente adaptada às condições climáticas e das terras do município, direciona a atividade agrícola local para 
produção desta commodity em escala comercial. O milho continua sendo produzido pelos agricultores, porém com a tecnificação agrícola sua produtividade foi elevada gradativamente.

$\Rightarrow 1990$ - A abertura do mercado internacional proporcionou a possibilidade de agregar valor ao produto agrícola por meio da diversificação das atividades agroindustriais. Com isso a cooperativa local amplia seu raio de ação, transformando-se em complexo agroindustrial, iniciando assim o processo de agroindustrialização do município.

$\Rightarrow 2006$ - Um grupo de 13 agricultores do município instala o primeiro condomínio agrícola no município de Palotina.

$\rightarrow 2016$ - É inaugurado o $4^{\circ}$ condomínio agrícola de armazém no município.

De acordo com a FAEP (2014) os condomínios agrícolas de armazéns surgiram inicialmente com o objetivo principal e comum entre os seus associados de redução dos custos com o processo de armazenagem, principalmente das taxas de desconto na entrega, e a possibilidade de comercialização da produção na época mais apropriada, fatores que gerariam maior rentabilidade agregada à produção.

Conforme identificou Fillipi (2017), inicialmente, a insatisfação dos condôminos estava relacionada à percepção crítica quanto à lucratividade das cooperativas e cerealistas sobre a produtividade armazenada pelos produtores cooperados e as taxas abatidas dos produtores para armazenagem do produto agrícola.

Quanto ao descontentamento dos produtores com o modelo cooperativo atual, verifica-se ainda que o arranjo produtivo local, ao introduzir o agronegócio como característica territorial, exigiu outra postura e novas estratégias por parte da cooperativa agrícola que já estava consolidada no município. Estas estratégias consistiam na diversificação e ampliação do modelo agrícola, verticalizando a cadeia produtiva de soja e milho, agregando valor à produção local mediante a industrialização e processamento de novos segmentos industriais.

Com a transformação da cooperativa em complexo agroindustrial, surge a diversificação agroindustrial no município, que trouxe para o círculo produtivo a opção da avicultura como alternativa frente aos desafios de ampliação de emprego e renda no município. Com esta estratégia, a cooperativa, agora complexo agroindustrial, buscou seu fortalecimento empresarial frente aos desafios da globalização e competitividade comercial, deixando de lado as características do seu modelo cooperativista original (de armazenagem e comercialização de grãos) e abraçando um projeto de modernização do agronegócio para atender a demanda externa da cadeia agroexportadora de alimentos industrializados.

$\mathrm{Na}$ medida em que a cooperativa investiu mais em fábrica de rações, frigorífico de carnes e outras agroindústrias, supõe-se que tenha deixado em segundo plano o investimento em armazéns, e, com isso, gerado um descontentamento por parte dos associados tradicionais produtores de grãos, para os quais as condições de armazenagem seriam mais importantes. Tais agricultores se reuniram, planejaram, pesquisaram e de fato atuaram para estabelecer um novo formato associativo que possibilitasse melhores rendimentos à jusante do plantio.

De acordo com o relato dos agricultores pesquisados, uma colhedora moderna tem capacidade para colher, em apenas um dia, o mesmo volume de área que há dez anos atrás demorava até uma semana para realizar o mesmo serviço. A agilidade na retirada do produto das áreas de plantio não foi acompanhada pela estrutura de recebimento. A constante carência de melhorias na estrutura de descarregamento e recebimento, em épocas de pico das safras, se agravou ano 
após ano, pois o desenvolvimento tecnológico não foi acompanhado pelo planejamento das empresas responsáveis pelo recebimento da produção.

A constante elevação da produtividade e a modernização dos implementos agrícolas exigiram readequação nas estratégias de recebimento e armazenagem por parte da cooperativa no município, fato que, segundo os condôminos, não ocorreu. Possivelmente, tenha ocorrido alguma ampliação na estrutura de armazenagem, mas a logística para a entrega e descarga do produto colhido, aspecto mais crítico, segundo os condôminos, continuava a penalizar o produtor.

De acordo com informações de produtores, um caminhão carregado chegava a permanecer até um dia inteiro na fila, aguardando para descarregar, enquanto hoje, no condomínio, de maneira ágil e organizada é possível fazer o mesmo processo em no máximo 20 minutos.

$\mathrm{Na}$ visão dos agricultores, de nada adiantaria a tecnificação na produção agrícola e na colheita se não ocorresse o mesmo com as práticas de recebimento e armazenagem da produção. As longas filas que se formavam para o recebimento da produção em épocas de colheita geravam desconforto e preocupação aos produtores agrícolas, pois os caminhões parados na fila significavam as colhedoras paradas nas lavouras - serviço postergado e prejuízo financeiro. Era necessária maior agilidade para o descarregamento do produto no seu destino de armazenagem.

De acordo com a pesquisa, a maior dificuldade encontrada pelos agricultores associados, para implantar o primeiro condomínio, foi a ausência de informações precisas quanto ao modelo associativo e suas características de formação, incluindo-se aí o desconhecimento das burocracias legais necessárias para a constituição do empreendimento.

Considerando a ausência da realização de algum planejamento administrativo estratégico pelo grupo, as dúvidas foram sanadas por meio de informações ou sugestões de terceiros. Segundo um dos condôminos, o apoio e orientação do gerente do banco foi de muita importância para a organização da documentação necessária para viabilizar o financiamento desejado naquele momento.

O montante investido no empreendimento foi obtido junto ao Banco Nacional de Desenvolvimento Econômico e Social (BNDES), via Banco do Brasil, por meio de duas linhas de crédito oficiais: FINAME Agrícola e MODERINFRA, com taxas de juros de 13,95\% e 8,5\% ao ano respectivamente.

O capital inicial investido com recursos próprios pelos condôminos foi de R\$300 mil, dividido em cotas individualizadas. Além deste valor, o grupo obteve ainda o financiamento de $\mathrm{R} \$ 2.800$ mil, em nome do condomínio e vinculado proporcionalmente à cota participativa de cada condômino.

O montante do recurso foi destinado à aquisição dos equipamentos capazes de atender a demanda de armazenamento dimensionada pelo grupo de associados e foi previamente estabelecida por cada participante em conformidade com o estatuto do condomínio.

Segundo relato de um condômino, ao analisar comparativamente a taxa de juros e as condições atuais de financiamento, concluiu que, mesmo com as altas taxas de juros contratadas naquele momento, o empreendimento, quando "colocado na ponta do lápis", seria viável, pois os desembolsos com transporte, armazenagem, secagem e a lucratividade com a comercialização do produto estocado geravam um rendimento total de aproximadamente $20 \%$ a mais que o armazenamento terceirizado.

O segundo condomínio formado no município, começou a ser idealizado em 2011 e buscou inspiração nos moldes e dados técnicos do primeiro condomínio, que neste período já se 
encontrava consolidado e em ampliação. A construção deste condomínio aconteceu em 2012 e também captou recursos financeiros nas mesmas linhas de crédito do seu antecessor, no entanto com taxas mais atrativas, 5,5\% a.a. para a construção das instalações (MODERINFRA) e de 2,5\% a.a. para a aquisição de equipamentos (FINAME).

A partir de 2013, com finalidade de apoiar o setor produtivo na ampliação da capacidade estática e melhoria do parque de armazenagem do país, o Governo Federal lançou um Programa para Construção e Ampliação de Armazéns (PCA) que disponibilizou recurso financeiro, em linha de crédito específica, para o financiamento de novas estruturas de armazenagem, reformas e modernização de unidades já existentes, com juros subsidiados, abaixo dos praticados no mercado e com prazo de 15 anos para pagamento, incluindo aí três anos de carência.

Os outros 2 condomínios agrícolas de armazéns instalados no município de Palotina se espelharam nos modelos dos condomínios que já estavam em funcionamento. Com isso, alguns contratempos foram evitados e até melhor resolvidos pelos novos grupos, pois quando surgiam dúvidas buscavam o apoio técnico necessário e a informação junto aos associados do primeiro e do segundo condomínio.

Com um Programa de Governo específico para a construção de armazéns, estes 2 novos condomínios foram favorecidos nas taxas de juros contratadas, pois foram instalados entre os anos de 2013 a 2015, quando o Programa para Construção e Ampliação de Armazéns (PCA) foi lançado e suas taxas se fixaram entre 3,5\% a.a. e $4 \%$ a.a.

Foi constatado, contudo, que o primeiro grupo teve maiores dificuldades em obter informações quanto aos dimensionamentos físicos e estruturais do empreendimento, o que se justifica pelo fato da novidade do modelo no universo do agronegócio regional. Estas dificuldades foram minimizadas quando da instalação do segundo condomínio e assim sucessivamente. Ao analisar os Regimentos Internos dos condomínios instalados, verificou-se algumas evoluções significativas entre eles, principalmente nos capítulos que determinam as composições das diretorias e o peso de participação definido por cotas.

\section{Estrutura de funcionamento dos condomínios de armazéns}

De acordo com a pesquisa realizada, as características físicas e estruturais dos quatro condomínios instalados no município de Palotina, de modo geral, guardam entre si muita semelhança. Sugere-se que isso tenha ocorrido devido ao fato de o primeiro condomínio em funcionamento servir de modelo aos demais.

A semelhança entre os quatro condomínios analisados também ficou evidenciada pela área destinada a cada empreendimento de aproximadamente 7,2 hectares. Três destes estabelecimentos estão localizados estrategicamente próximos a rodovias intermunicipais, em local que, segundo informações obtidas, foi previamente escolhido entre os condôminos e adquirido com o objetivo de favorecer a logística da maioria deles, além de facilitar o acesso aos compradores quando da comercialização e retirada do produto.

Quanto aos equipamentos, as diferenças verificadas estão relacionadas à capacidade de armazenamento total de cada condomínio. São compostos por: a) equipamentos para a limpeza e secagem do produto; b) correias transportadoras e equipamentos para o deslocamento interno do produto durante todo o fluxo de armazenagem, carregamento e descarregamento; c) Estruturas e equipamentos para a realização de todo o processo, desde o recebimento até a armazenagem e expedição do produto. 
Os equipamentos instalados são responsáveis por 5 etapas distintas do processo de armazenagem do produto: 1) Recebimento; 2) Limpeza; 3) Secagem; 4) Armazenamento e 5) Expedição.

O custo estimado para a armazenagem do produto, contabilizando as despesas com toda a infraestrutura do condomínio, desde o momento da entrada do produto até a sua retirada, é de aproximadamente $\mathrm{R} \$ 1,80$ (um real e oitenta centavos) para cada saca de $60 \mathrm{Kg}$ de milho e de aproximadamente $\mathrm{R} \$ 1,30$ (um real e trinta centavos) para cada saca de $60 \mathrm{Kg}$ de soja, este valor é estimado no espaço de tempo de 6 meses.

De acordo com o Regimento Interno, em todos os condomínios é determinado um prazo limite para a retirada do produto ensilado, em geral este prazo é de aproximadamente 6 meses, uma vez que a produção agrícola do município de Palotina, se intercala anualmente entre soja e milho.

Após este período, caso o condômino ainda permaneça com o seu produto armazenado, há a cobrança de uma taxa de $0,3 \%$ ao mês por saca de produto estocado.

De acordo com o Regimento Interno dos condomínios agrícolas analisados, os associados devem eleger os membros das suas diretorias a cada dois anos que poderão, no todo ou em parte, serem reeleitos indefinidamente. Em três destes condomínios a diretoria é composta por: presidente; vice-presidente; secretário; tesoureiro.

No quarto condomínio, o último a ser instalado, se verificou que ocorreram alterações nesta composição, exigindo maior participação dos associados e também flexibilizando a composição da diretoria, deste modo, segundo seu Regimento Interno fazem parte da diretoria: síndico; secretário; tesoureiro; 2 (dois) suplentes. Conforme se verifica, neste condomínio não há o cargo de vice-presidente que foi substituído pela inclusão de 2 (dois) suplentes. De acordo com a que determina o Regimento Interno deste condomínio, o secretário é o substituto imediato do síndico, aos suplentes cabe a função de substituir apenas secretário e tesoureiro. No regimento interno deste mesmo condomínio ainda se verificou a possibilidade da eleição, como membro da diretoria, além do condômino, qualquer representante do seu grupo familiar, desde que autorizado pelo titular da cota.

Percebe-se com isso que com o passar do tempo houve a necessidade também de ajustes no organograma dos condomínios. A possibilidade da participação de membros das famílias associadas, mediante a autorização do titular, de colocar seus nomes a disposição para ocupar algum cargo diretivo permite maior integração entre os associados e familiares envolvidos no empreendimento, sugerindo uma ampliação das opções de compartilhamento de conhecimento entre os atores envolvidos.

Dentre as atribuições coletivas da diretoria eleita está a responsabilidade de nomear ou contratar funcionários para o setor administrativo e operacional.

Verificou-se que nos condomínios agrícolas a mão-de-obra terceirizada contratada é constituída por cinco ou seis postos de trabalho fixos, dependendo do tamanho da estrutura física do condomínio. Em períodos de colheita, onde os trabalhos são mais intensos, são contratados alguns postos temporários, geralmente contratados como diaristas, para postos de auxiliar operacional. Os postos fixos de trabalho, contratados nos condomínios são: gerente; assistente administrativo; 2 (dois) ou 3 (três) auxiliar operacional; zeladora. 


\section{Considerações finais}

Destaca-se a tradição em relação à organização social e coletiva no espaço agrícola de Palotina e os resultados alcançados para a viabilidades da produção de soja e milho. A primeira cooperativa agrícola foi fundada em 1963. Na segunda década do século XXI, os agricultores continuam em associação, mas com "novos" modelos, a exemplo dos condomínios de armazéns.

o que curiosamente se verifica quanto ao surgimento dos condomínios agrícolas de Palotina é que basicamente os mesmos motivos que levaram os pioneiros a se unirem e fundarem a cooperativa em meados da década de 1960, também foram os motivos que levaram os agricultores estabelecerem o primeiro condomínio agrícola do município em 2006, o descontentamento com a lucratividade da produção e a deficiência logística e de armazenagem agrícola.

A continuidade deste estudo permitirá mensurar os benefícios administrativos da implantação de condomínios de armazéns em Palotina, do ponto de vista econômico, social e ambiental, bem como na dinâmica regional e agropecuária e no perfil socioeconômico e cultural dos agricultores envolvidos.

\section{Referências}

ANJOS, F. S. dos; ESTRADA, E. M.; CALDAS, N. V. Family Farming and Economic Cooperation: the emergence and decline of agrarian condominios in southern Brazil. Journal of Rural Social Sciences, v. 26, n. 2, p. 30-51, 2011.

BRASIL. Decreto no 3.993, de 30 de outubro de 2001. Regulamenta o art. 95-A da Lei no 4.504, de 30 de novembro de 1964, que institui o Programa de Arrendamento Rural para a Agricultura Familiar, e dá outras providências. Coletânea de Legislação. Disponível em: <http://www.planalto.gov.br/ccivil_03/ decreto/2001/D3993.htm> Acesso em 09 nov. 2019.

CARDOSO, U. C.; NOGUEIRA, V. L.; RODRIGUES, E. R. Q. Cooperativa: série empreendimentos coletivos Brasília, DF: Sebrae, 2014, 62 p.

FAEP - Federação da Agricultura do Estado do Paraná. Boletim Informativo. Ano XXVIII, n. 1280, out. 2014.

FILIPPI, A. C. G. Caracterização e análise da viabilidade de Condomínios de Armazéns Rurais: um estudo Multicaso. 2017, 204 f. Dissertação. (Mestrado em Agronegócio) - Faculdade de Agronomia e Medicina Veterinária, UNB, Brasília, 2017.

GULLO, M. C. R. Condomínios rurais: uma alternativa para a viabilização da pequena propriedade rural. São Leopoldo: UNISINOS, Centro de Ciências Econômicas, 1997, 86 p.

HESPANHOL, N. A. O Desenvolvimento do Campo no Brasil. In: FERNANDES, B. M. (Org.) et al. Geografia Agrária: Terra e Poder. São Paulo: Expressão Popular, 2007, p. 281-287.

HUMMELGEN, B. Cooperativismo: um agente de mudança. Revista Urutágua - Revista Acadêmica Multidisciplinar, Maringá, ano 2016, n. 34, jun./nov. 2016.

INSTITUTO BRASILEIRO DE GEOGRAFIA E ESTATÍSTICA - IBGE. Cidades - Palotina. Disponível em: <https://cidades.ibge.gov.br/brasil/pr/palotina/panorama> Acesso em: 09 nov. 2019.

INSTITUTO PARANAENSE DE DESENVOLVIMENTO ECONÔMICO E SOCIAL - IPARDES. Cadernos Municipais. Disponível em: <http://www.ipardes.gov.br/index.php?pg_conteudo=1\&cod_ conteudo=30> Acesso em 09 nov. 2019. 
MACEDO, A. dos S.; SOUZA, D. N. de; AMODEO, N. B. P. A Organização do Quadro Social na Interface entre Gestão Empresarial e Social de Cooperativas. Desenvolvimento em Questão, v. 12, n. 26, p. 177205, mar/2014.

NANTES, J. F. D.; SCARPELLI, M. Elementos de Gestão na Produção Rural. In: BATALHA, M. O. (Coord.). Gestão Agroindustrial. 3. ed. São Paulo: Atlas, 2012, p. 629-664.

OLIVO, C. J. Sustentabilidade de Condomínios Rurais Formados por Pequenos Agricultores

Familiares: Análise e Proposta de Modelo De Gestão. 2000. 269 f. Tese (Doutorado em Engenharia de Produção) - Universidade Federal de Santa Catarina, Florianópolis, 2000.

REGINATO, P. História de Palotina 1954/1979. Santa Maria: Palloti,1979.

SAQUET, M. A.; SPOSITO, E. S. Território, Territorialidade e Desenvolvimento: Diferentes Perspectivas no Nível Internacional e no Brasil. In. ALVES, A. F.; et al. (Org.). Desenvolvimento Territorial e Agroecologia. São Paulo: Expressão Popular, 2008, p. 15-31.

SENAR. Serviço Nacional de Aprendizagem Rural. Associações Rurais: Práticas Associativistas, Caracterização e Formalização. Brasília: SENAR, 2011. Disponível em: <http://www.senar.org.br/sites/ default/files/153_-_associacoes_rurais_0.pdf> Acesso em: 09 nov. 2019.

SILVEIRA, D. T; CÓRDOVA, F. P. A pesquisa científica. In: GERHARDT, T.; SILVEIRA, D. T. Métodos de pesquisa. Porto Alegre: Editora da UFRGS, 2009, p. 31-42.

TOMAZELLA, P. D.; SCHALLENBERGER, E. A exploração territorial do município de Palotina, Oeste do Paraná, e o remanescente florestal. Tempo da Ciência, v. 17, n. 34, p. 71-83, 2010. 